\title{
INSCRIPTIONS COPIED BY COCKERELL IN GREECE.
}

I HAVE been requested to examine a MS. collection, bound in two volumes, and entitled MSS. Inscriptions collected in Greece by C. R. Cockerell, 1810-14. ${ }^{1}$ A fuller description of the contents is added on the title page, apparently by the hand of the collector himself-'Inscriptions collected in various parts of Greece by C. R. Cockerell, fiom the year 1810-14; they were copied from the original manuscripts in this form by Signor Amati, in Rone, in 1815, and examined by Mr. Akcrblad, who made all the notes and corrections in red ink. Mr. Walpole has made copies of those marked "Cd.," and has noted those already in print.' It is evident, therefore, that we have here documents of considerable importance, especially as all trace of the original manuscripts referred to has been lost. Signor Amati, the transcriber, seems to have done his work with great care and accuracy, even the forms of letters being, in most cases, faithfully preserved. A comparison with other independent transcriptions from the same originals will soon show that we may rely on his copying; where mistakes occur, they are almost always such as would arise from indistinctness on the stone itself. This statement is of importance, for other transcribers, whether

1 [On the occasion of one of his lectures at University College, $\mathrm{Mr}$. Newton asked his auditors to let him see any MS. collections of inscriptions lying in private possession of which they might be aware, such collections having been commonly made by English travellers in past times, and often merely laid aside. As a result of this ripuest, Mrs. Freleric's Cockerell sent to Mr. Newton the collection here described of inscriptions copied by her father-in law, Mr. C. R. Cockerell. The laborious and somewhat unattractive task of investigating whether these inscriptions were unpublished, or whether they amended existing texts, was undertaken, on behalf of the editors of this journal, by Mr. E. A. Gardner. Ed.] 
independent or immediately deriving their material from this book, often show a carelessness which can easily be corrected by a reference to it, and which has, in many cases, affected the copies preserved in the Corpus itself.

The book contains 240 inscriptions in all, of which some fifty, probably, are as yet unpublished. This computation may have to be modified, but is confirmed by a more careful search for the earlier ones. The rest afford considerable material for correction of the copies preserved in the Corpus and elsewhere, but are hardly, in most cases, worth separate publication. ${ }^{1}$ They enable us, also, to check the accuracy of copies derived immediately from this book, especially those of Walpole; and such a check is by no means superffuous. For instance, in C.I.G. 391, derived from Walpole, common forms are given throughout; in this book we find $A A, \Delta, \lambda, Z, \sqsubset$; again, in C.I.G. 464, the distinctive forms $A, \epsilon, \lambda, C, \omega$, are completely lost. One more instance under this head may suffice. In C.I.G. 1593, Walpole represents Cockerell as giving BOI $\Omega$ T $\Omega$ NTA . . .

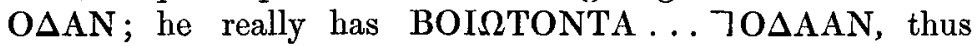

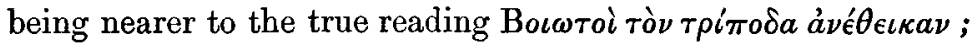
here, in $\Omega N$, Walpole has given as resting on good authority a false and misleading emendation, which is written in red ink above the line in Cockerell's book. It is therefore clear that a careful collation is advisable in the case of all inscriptions in the Corpus derived from this source.

Another question arises which cannot be fully answered until more of our material has been published. Many English travellers of the beginning of the present century seem to have examined this book of Cockerell's; Akerblad, Walpole, and Leake, have all left traces of their revision in it; and some of these drew from it the inscriptions which they published. How far others may have done the same is not yet clear; but in C.I.G. 1707, for instance, a transcription quoted in the Corpus as made directly by Hughes from the stone, shows too many correspondences, even in mistakes, with Cockerell's version for us to believe the two versions are independent. In 1. 6, for instance, Hughes gives ANE1 1 HITON for ANE A Cockerell has ANEIATTON, differing only from the true reading

I A collation with published copies has been made in the case of all not her reproduced. 
by the omission of part of the $\phi:$ but over the line is written the very emended form given by Hughes in his copy. This fact, which is not isolated, tends to throw serious doubts on the independent value of such copies. Perhaps it will be worth while later to return to this question; for the present, this indication will suffice.

Specimens follow of such inscriptions as are new, and, therefore, worthy of reproduction; some are included which materially increase already published inscriptions. These specimens comprise all that were found upon the mainland of Greece, and are taken from the first sixty examples in Cockerell's book. A complete list of these follows. An asterisk is placed against those reproduced below.

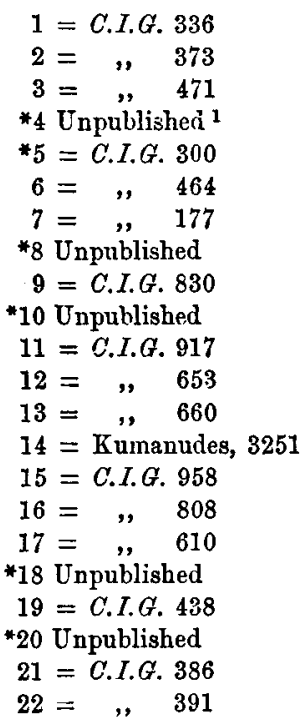

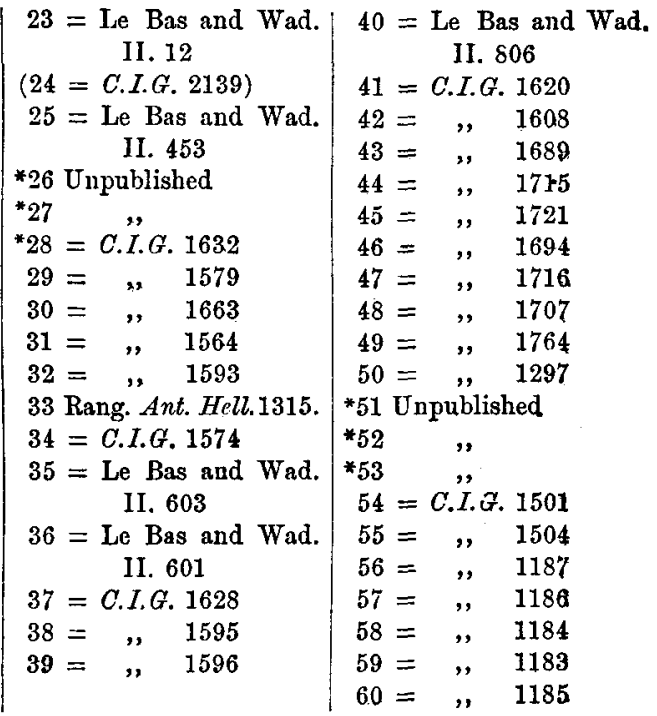

Before proceeding to the inscriptions themselves, I need only add that a few marks, both in pencil and red ink, are

1 Inscriptions not to be found in the new or old Corpus, in I.e Bas and Waddington, in Kumanudes' Scpul. chral Inscriptions, in Rangabé's $A n$ tiquites Helleniques, \&c., are here treated as unpublished. I have also referred

H S.-VOL, VI. to periodicals, where I had any clew to guide mo; but a complete and systematic search through all these would have been laborious and aimost impracticable. 
found in the book as well as Amati's copies : but these are seldom, if ever, more than obvious restorations, and do not seem to have any authority from the original manuscripts, or other sources. Signor Amati has sometimes recorded in Italian both the place of finding and other details; these have been, in every case, reproduced below. Inconsistencies in his copies, especially when two forms of a letter occur in the same inscription, have also been as far as possible preserved.

\section{Z $\Omega \Sigma I M H K A \Lambda \Lambda I N I K O Y M I \Lambda H \Sigma \mid A$ $\phi \Omega K I \Omega N O \Sigma O T P Y N E \Omega \Sigma E Y N H$}

\section{$\mathrm{Z} \omega \sigma i \mu \eta \mathrm{K} a \lambda \lambda \iota \nu i \kappa o v \mathrm{M} \iota \lambda \eta \sigma i a$

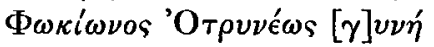

The name Z $\omega \sigma i \mu \eta$ seems to have been common among Milesians ; ef. C.I.G. 711, 712, 714. For the question whether Miletus ranked as a deme of Athens, and the Milesians as Athenian citizens, cf. Boeckh, ibid. 692. A discussion of more recent opinions upon the subject is given by Mr. Hicks (Brit. Mus. Inscriptions, I. p. 150). It seems that Milesians, though very numerous at Athens, had no peculiar rights of citizenship; even the form of the inscription, with the local name in the fem. nom. instead of the masc. gen., to agree with the father's name, would be unusual for an Attic deme. Intermarriages such as that here recorded have been adduced as evidence for the Athenian citizenship of Milesians, but the balance of authority seems to be on the other side.

5. This is identical with C.I.G. 300, but preserves so much more of the original that it seems worth while to add a new transcription.

In tre corone:-

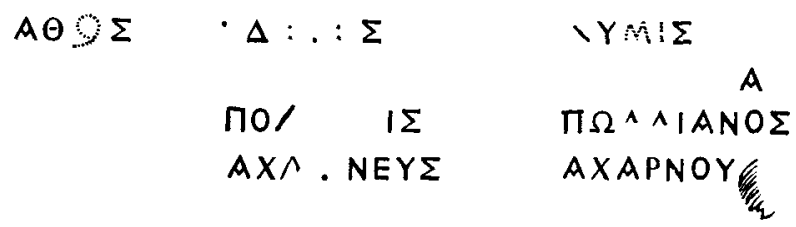




\begin{tabular}{|c|c|c|}
\hline OEENOE & BAKXIOE & $\triangle 1 O \Sigma$ \\
\hline JА $\Omega N I O \Sigma$ & 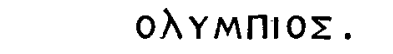 & $\Sigma: H I: O \Sigma$ \\
\hline IПATPOE & $\triangle H M O \Sigma C=1: \cdots:$ & $K \wedge \equiv|\Delta|=$ \\
\hline$\wedge \Omega N \mid \wedge \Sigma$ & AONYEIOE & $\triangle I O K \wedge H \Sigma$ \\
\hline$V=: I \Sigma$ & $\Xi:: P . O \Sigma$ & $X: \Delta 0 \phi \Omega N$ \\
\hline$O \Sigma$ & I:E : : : : : & AПO $\triangle \wedge \Omega N O \Sigma$ \\
\hline$\wedge \Omega N O \Sigma$ & $\phi \mid \wedge A-1: O \Sigma$ & 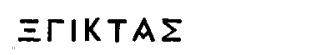 \\
\hline MENOE & 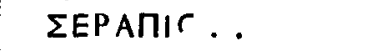 & 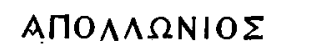 \\
\hline$=$ & $\mid \Sigma A \Sigma$ & AMAPANTOE \\
\hline$\Lambda A \Sigma$ & MAPAMONOE & $\Lambda^{2} K O \Sigma$ \\
\hline $2 N$ & $A \cap O \wedge \wedge O N I \triangle H \Sigma$ & HAIO $\triangle \Omega P O \Sigma$ \\
\hline$\Sigma 10 \Sigma$ & $A \equiv I O \Sigma$ HPAKA & $N I K \Omega N$ \\
\hline -orr & IEIKOKPATOY. & \\
\hline
\end{tabular}

Nel giardino della кúpa Kovтрıкôิ.

(Sic; altered in pencil to $\kappa \nu \rho a ̀$ Kot-.)

The dotted line indicates the amount extant in the C.I.G. copy. It will be observed that in one case $\lambda$, in two $A$ is given, probably by mistake.

If the inscriptions in the three wreaths belong to the text below them, they may help to explain these mere catalogues, of which several occur in the Corpus. In the second wreath we have $\Delta \ldots . . . s \Pi o[\ldots] s$ 'A xapvev́s; in the third; - -s $\Pi \omega \lambda \lambda i^{\prime a \nu o s}$ 'A $\chi \alpha \rho \nu[\epsilon] v[s]$. In the new columns are clear the names

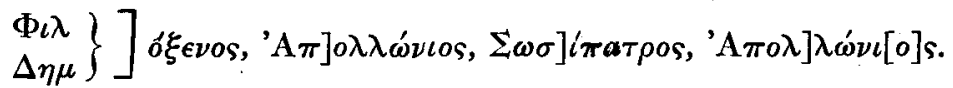

The rest are too fragmentary for probable restoration. Turning next to the part preserved also in the Corpus, we find, in the left column 1. 1, the conjecture Bák $\chi$ ıos confirmed; in 1.5 the -os confirms again Boeckh's emendation. In 1.9 we find 'I $\sigma a \hat{s}$ for 'I $\sigma i a s$. In 1.7 Cockerell's transcript suggests $\Phi \iota \lambda a ́ \delta \in \lambda \phi o s$; this is confirmed by 'A $\delta \in \lambda \phi o ́$ s in 1.6 of C.I.G., if one may assume a confusion of the two lines.

In the right column we find, l. 6, the form 'Amo $\lambda \lambda$ ' $^{\prime} \nu$ os, and in 10, $\Lambda$ v́кos quite clear, thus confirming Boeckh's emendation in both cases. 
148 INSCRIPTIONS COPIED BY COCKERELL IN GREECE.

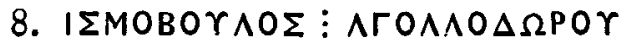

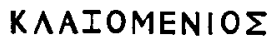

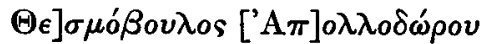

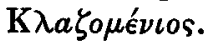

The form of $\zeta, I$, indicates an earlier period; also, probably, $\Gamma$, which has often, in other cases, been mistaken for $\Gamma$ by the transcriber.

$$
\begin{aligned}
& \text { 10. ТОВОҮАН } \\
& \Sigma \Sigma \Gamma I K H \\
& \text { 'А } \iota \sigma] \tau o \beta o v ́ \lambda \eta \\
& \Theta \epsilon] \sigma(?) \sigma \pi \iota \kappa \eta '
\end{aligned}
$$

If the second word be rightly restored, we have here a peculiar form of the adjective. For the $\Sigma \Sigma$, on the accuracy of which, however, too much stress must not be laid, cf. Boeckh on C.I.G. 25. Such doubling is found both in Attic and Bocotian inscriptions.

\section{IEPOK $A H \Sigma$ \\ חOPIOE

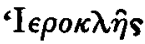 \\ ПIóplos.}

Poros is a deme of the tribe Akamantis.

Above this is written 'Vaso,' by the original copyist. This probably means that the inscription was on one of the marble lekythi often found on tombs in Attika.

This, and all that precede it, seem to come from Athens.

20. Apparently from Eleusis; those before and after it certainly are so ; and geographical order is usually preserved.

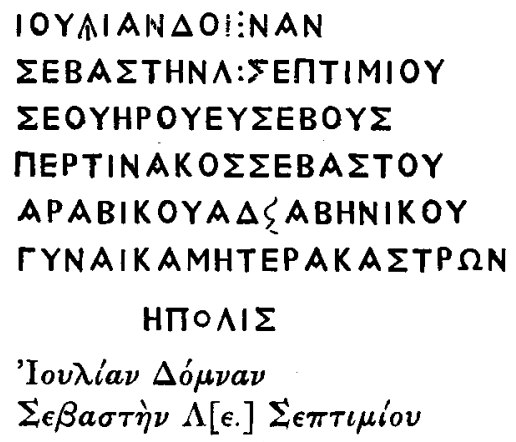


INSCRIPTIONS COPIED BY COCKERELL IN GREECE. 149

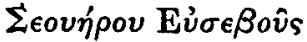

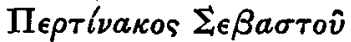

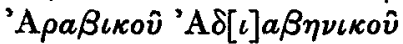

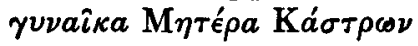 \\ $\dot{\eta} \pi \dot{\lambda} \iota \iota$.
}

This string of titles of Septimius Severus is found pretty frequently repeated. Julia Domna's last title is found both in this merely transliterated form, and also in the translated one,

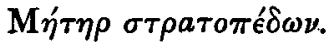

26. 'In Platea,' written over 25 , but probably applies to this also, which is transcribed immediately underneath. $\lambda$ and $\Lambda$, $A$ and $\mathbf{A}$, occur with strange inconsistency in the copy.

TILח $\lambda$ ATAIANLY $\lambda H\left[E N T I E^{* V} A E L E N O P M O N\right.$. AMANTWN

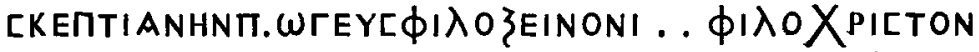
OYNEKENENMAPADILWLY. AOANATOIL $\lambda$. XEK $\lambda H P O N$ A YTHK AITOCEICOI. ON $\triangle E A I$ VITOTAQON

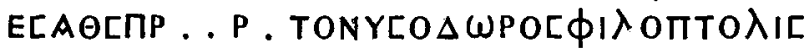

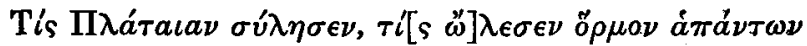

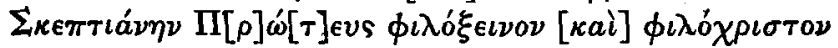

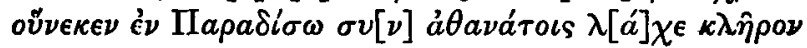

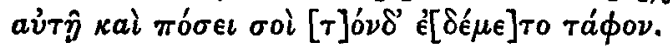

$\Delta \iota] o \nu v \sigma o ́ \delta \omega \rho o s ~ \phi \imath \lambda o ́ \pi \tau o \lambda \iota s$

' Who robbed Platea, who destroyed that refuge of all Skeptiane, daughter of Protes, friend to strangers and to Christ? Since she hath won a portion with the immortals in Paradise, for herself, and thee, husband, she built this tomb.'

If the restoration $\epsilon^{\prime} \delta \epsilon^{\prime} \mu \bar{c} \tau o$ in 1.4 is right, it is scarcely harsher

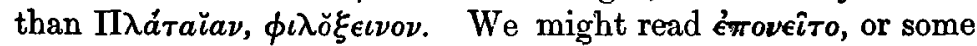
such word, but this would depart further from our copy. The pentameter following three hexameters is hardly unusual. Other obvious irregularities of scansion hardly call for remark in such an inscription.

27. Perhaps still Platea; at any rate Boeotia, as the next is 'in Tebe.' 
5.

ГAMфINOY AC)

IKIANOCZWTYYPOY

AXKOMENEIC $\wedge Y K O C$ )

$O C$

IEIAITIWN

APKOYNTOC $\triangle E H N A T W N O Q E T R$

PODEICOYE

10. ПOP - ГMMMENOIKPATEIN

OY... TФINOKPATHCKAIOC.

Not much seems intelligible beyond the words, $1.8, \delta \dot{e} \boldsymbol{\eta} \nu$

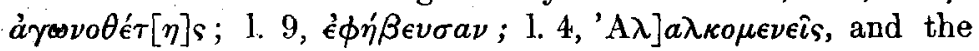

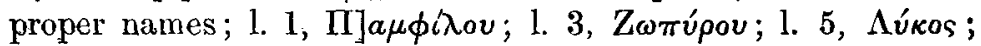

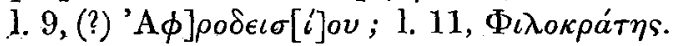

In 1.7 , one is reminded of the formula ' $\left.\tau \iota \nu \grave{s} a^{a} \gamma a \theta 0 \hat{v} \dot{a}\right] \epsilon i$ aiтi $\omega \nu[\gamma \in \nu o, \mu$ ć $\nu \omega \nu$;' but this has not otherwise the appearance of a complimentary inscription.

28. C.I.G. 1632.

Cockerell gives a line, wanting to the sense which is absent in the C.I.G. ; $1.1,1$ inserted after second $\Lambda ; 1.3$, the 1 supplied after the first $\mathrm{T}$ in C.I.G. is given by Cockerell ; between 1. 4, and 1.5.

\section{$\triangle$ HMOYAPIETATT}

Thus we read the whole

$$
\begin{aligned}
& \text {...á } \lambda \lambda \iota{ }^{\circ} \Phi a v
\end{aligned}
$$

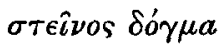

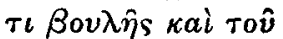

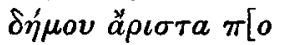

$$
\begin{aligned}
& \lambda \epsilon \iota \tau \epsilon U \sigma a ́ \mu \epsilon
\end{aligned}
$$

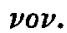

The fourth line seems to have been dropped from the letter $\Delta$ apparently beginning both it and 1. 5 .

51. This and also 52, are immediately beneath an inscription found 'in Messene.' 
152 INSCRIPTIONS COPIED BY COCKERELL IN GREECE.

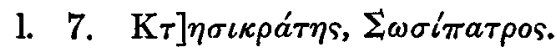

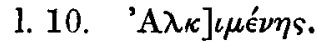

1. 11. $\Delta$ a

1. 13. Ka Kaî́s,

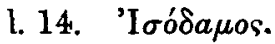

1. 16. 'Е

1. 18. K $\rho \eta] \sigma i \lambda a s$.

This, probably, also belongs to Messene, as it follows immediately on 51 and 52. 54 was found 'in Sparta.'

ERnest A. Gardner. 